\title{
Efficacy of Ozone Therapy in the Treatment of Tinnitus: A Systematic Review
}

Najadir Cristina De Faria GC *

Victor Gualberto VC,

Sergio Bruzadelli M,

Fayez Bahmad JR

\begin{abstract}
Background: Tinnitus is a frequent complaint in otorhinolaryngology. The symptoms of tinnitus those are severe enough to significantly affect the quality of life. Numerous therapeutic interventions and studies claim success in the treatment of tinnitus, but the cure remains undefined. However, ozone therapy has been suggested as potential treatment for tinnitus.

Objective: This systematic review aims to investigate the efficacy of ozone therapy in the treatment of tinnitus.

Material and Methods: A systematic search was performed in MEDLINE, Web of Science, Cochrane Library, Science Direct, Scopus, Google Scholar, Embase and LILACS. Data was processed by two independent reviewers. Only Systematic Reviews, Randomized Controlled Trials, Observational Studies and Case Series published in English or Spanish with no date limit that evaluated the use of ozone therapy for the treatment of tinnitus were included.
\end{abstract}

Results: From 264 references retrieved after duplicates removal, 260 articles were excluded according to the pre-established selection criteria. The assessed articles were then subjected to risk of bias analysis, and one of them was excluded.

Conclusions: High-level evidence, such as well-conducted randomized clinical trials, are still needed to confirm the efficacy and safety of this therapy

Keywords: Tinnitus, Ozone, Ozone therapy 


\section{INTRODUCTION}

The current literature describes tinnitus as a "phantom auditory perception" resulting from atypical activities of the nervous system produced without any internal or external acoustic stimulation ${ }^{1,2}$. However, the mechanism involved is only partially understood ${ }^{3,4}$. The often-accepted theory describes the initial existence of a neuroplastic response to the absence of sound, which is perpetuated by a subsequent cascade of neural changes in the central auditory system ${ }^{5}$.

Tinnitus is a frequent complaint in otorhinolaryngology outpatient clinics and orofacial pain clinics ${ }^{3,6}$. Studies have shown that approximately $5.1-42.7 \%$ of the adult population reports tinnitus episodes ${ }^{7}$. A significant portion of these individuals have symptoms that are severe enough to significantly affect their quality of life. Work disability and sleep disorders are among the situations that patient's experience, and there are reports of mental disorders in some patients.

Numerous therapeutic interventions and studies claim success in the treatment of tinnitus, but the cure remains undefined ${ }^{6}$. There are several potential treatment options, such as transcranial direct current stimulation, ginkgo biloba and surgeries, which offer patients varying degrees of improvement in symptomatic complaints and quality of life $^{8-11}$. Ozone therapy is one therapeutic approach that has been shown to be promising for the treatment of tinnitus ${ }^{12-15}$.

Ozone therapy is a medical treatment that uses a gaseous mixture of ozone and oxygen (5\% ozone and $95 \%$ oxygen $)^{16}$ to activate mediators of nuclear signal transduction, thus acting via an indirect pharmacological mechanism ${ }^{16,22}$. In recent decades, $\mathrm{O} 3$ therapy has been widely used, and currently, its biological mechanisms of action, pharmacodynamics and biochemistry have reached consistent scientific levels ${ }^{17-19}$.

Ozone (O3) is normally present as a three-atom oxygen gas with a cyclic structure and can be produced by a medical generator from pure oxygen ${ }^{20}$. It activates molecular pathways that regulate endogenous antioxidant systems and is used as an auxiliary treatment, especially in pathologies in which the inflammatory process plays an important role and ischemia is an etiological factor ${ }^{21-23}$. Therefore, it has been shown to be especially effective in the treatment of various diseases, such as osteoarthritis and chronic wound recovery, and in the treatment of peripheral vascular disease $\mathrm{e}^{24,25}$.

Recent studies conducted worldwide show that ozone therapy has been used with high safety and efficacy in everyday clinical practice and is an important form of treatment ${ }^{17,22,26,27}$. In a comprehensive review, Noel $L$. Smith et al. concluded that a large amount of research provides evidence that the dynamic resonance structures of ozone facilitate physiological interactions that are useful in the treatment of a multitude of pathologies ${ }^{17}$. In a systematic review on the application of ozone for the treatment of chronic wounds, Fitzpatrick et al. concluded that this therapy is safe, and therefore, no adverse effects have been reported that are directly due to ozone therapy ${ }^{25}$.

Since March 2018, the Brazilian Ministry of Health has expanded its policies for integrative health practices in the Brazilian public health system (Unified Health System, SUS) and has authorized the inclusion of ozone therapy among the new types of integrative practices within the framework of procedures available in the SUS. Thus, the use of integrative practices for patients with chronic noncommunicable conditions that do not present clinical outcomes favorable to conventional treatments is justified ${ }^{28,29}$. In this scenario of advances and scientific evidence, the present review aims to investigate the efficacy of ozone therapy in the treatment of tinnitus (Table 1).

\section{METHODOLOGY}

This study consists of a systematic review conducted to answer the following clinical question: What is the efficacy of ozone therapy in the treatment of tinnitus? The present study was filed and registered on 09/29/20 under the code CRD42020177572 in International Prospective Register of Systematic Reviews (PROSPERO).

Eligibility criteria: Following the guidelines defined by the Preferred Reporting Items for Systematic Reviews and Meta-Analyses (PRISMA) Statement and the Population, Intervention, Comparator, Outcomes and Study Types (PICOs) model, eligibility criteria and search terms were developed to include articles published in English or Spanish with no date limit that evaluated the use of ozone therapy for the treatment of tinnitus. Studies classified as case reports, conference proceedings, literature reviews, book chapters or preclinical trials were not included in this review.

\section{Search strategy:}

The virtual search was performed between April and June 2020 in the following databases: MEDLINE, Web of Science, The Cochrane Library, Science Direct, Scopus, Google Scholar, Embase and LILACS. The descriptors used were (tinnitus [Title/Abstract]) AND ((ozone[Title/ Abstract]) OR (ozonetherapy[Title/Abstract])). Emtree terms (Embase Subject Headings) were used for the Embase search, and DeCS (Health Sciences Descriptors) were used for LILACS. MeSH (Medical Subject Headings) terms were preferred for the other cited databases.

Once the search for articles addressing the topic was performed, the references of the identified articles were included in the Rayyan QRCl database, and two independent reviewers read all abstracts and selected articles according to the inclusion and exclusion criteria. These selected articles were then read by all authors, and if more articles were identified for exclusion, the reason for exclusion was cited (Figure 1). 
Table 1: Showing the details of author, year of publication, location, study design, sample. size and outcomes.

\begin{tabular}{|c|c|c|c|c|c|}
\hline \multicolumn{6}{|c|}{ Study characteristics } \\
\hline $\begin{array}{c}\text { Country and } \\
\text { Year }\end{array}$ & Authors & Study design & Objectives & $\begin{array}{l}\text { Sample } \\
\text { number }\end{array}$ & Outcomes \\
\hline $\begin{array}{l}\text { Havana, } \\
\text { Cuba } \\
2012\end{array}$ & $\begin{array}{l}\text { Silvia Menéndez, } \\
\text { Alejandro } \\
\text { del Cerro, } \\
\text { Tania Alvarez } \\
\text { e Francisco } \\
\text { Hernández }\end{array}$ & $\begin{array}{l}\text { Quasi- } \\
\text { Experimental } \\
\text { Studies }\end{array}$ & $\begin{array}{l}\text { To evaluate the } \\
\text { effectiveness of } \\
\text { ozone therapy in the } \\
\text { treatment of peripheral } \\
\text { vestibulocochlear } \\
\text { syndrome }\end{array}$ & 50 patients & $\begin{array}{l}\text { They report the improvement of patients according to } \\
\text { vertigo, hearing loss, tinnitus and nystagmus, of } 90 \% \text {, } \\
80 \%, 65 \% \text { and } 100 \% \text {, respectively. They conclude that } \\
\text { ozone therapy is effective in the treatment of peripheral } \\
\text { vestibulocochlear syndrome. } \\
\text { * No side effects were observed. }\end{array}$ \\
\hline $\begin{array}{l}\text { Kayseri, } \\
\text { Turkey } \\
2013\end{array}$ & $\begin{array}{l}\text { Onur Sonmez, } \\
\text { Ismail Kulahl, } \\
\text { Alperen Vural, } \\
\text { Mehmet I'Ihan, } \\
\text { Mesut Aydın }\end{array}$ & $\begin{array}{l}\text { Randomized } \\
\text { Controlled } \\
\text { Trials }\end{array}$ & $\begin{array}{l}\text { Evaluation of the } \\
\text { effectiveness of } \\
\text { treatment with ozone } \\
\text { and beta-histamine in } \\
\text { the treatment of tinnitus }\end{array}$ & 68 patients & $\begin{array}{l}\text { The authors report that the study does not provide } \\
\text { sufficient evidence to support ozone and beta-histatin as } \\
\text { a treatment for tinnitus. } \\
\text { * No side effects were observed. }\end{array}$ \\
\hline $\begin{array}{l}\text { Bydgoszcz, } \\
\text { Poland } \\
2004\end{array}$ & $\begin{array}{l}\text { Katarzyna } \\
\text { Pawlak-Osinska } \\
\quad \text { et al }\end{array}$ & $\begin{array}{l}\text { Quasi- } \\
\text { Experimental } \\
\text { Studies }\end{array}$ & $\begin{array}{l}\text { To evaluate the } \\
\text { effectiveness of ozone } \\
\text { and pressure pulse } \\
\text { in the treatment of } \\
\text { Ménière's disease }\end{array}$ & 15 patients & $\begin{array}{l}\text { The authors report that the patients' subjective status } \\
\text { improved and there was a reduction in the frequency and } \\
\text { severity of tinnitus. }\end{array}$ \\
\hline
\end{tabular}
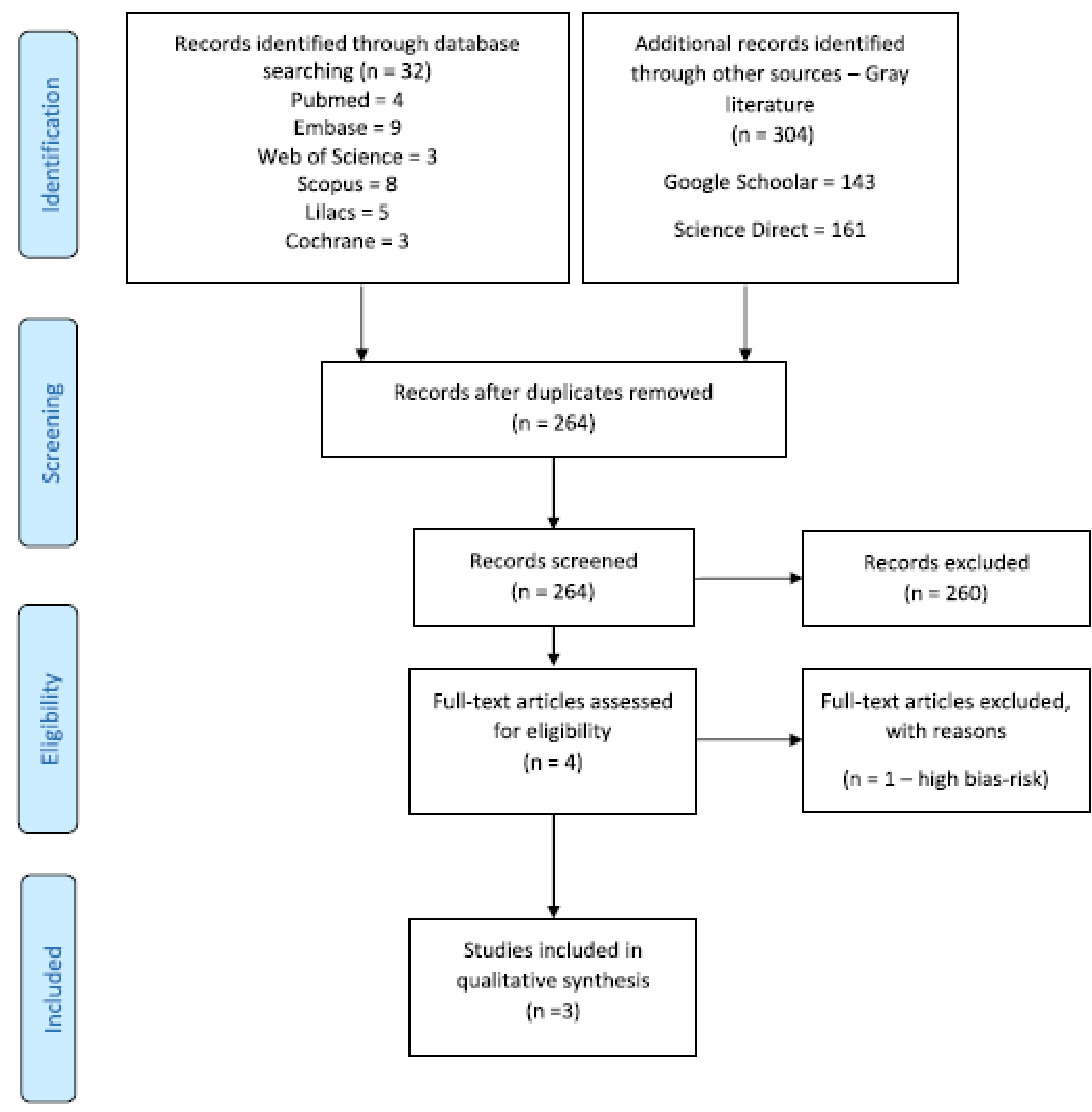

Figure 1: Prisma flow diagram. 


\section{Risk of Bias:}

To evaluate the risk of bias of the selected articles, the Joanna Briggs Institute (JBI) Critical Appraisal Tools questionnaires were used for randomized, quasirandomized studies and case series. See supplementary material.

These checklists have four response options: $Y$ for yes, $\mathrm{N}$ for no, $\mathrm{U}$ for unclear, and NA for not applicable. The risk is calculated as the percentage of $Y$ answers to the questions on each list according to the JBI guidelines.

A risk of up to $49 \%$ is considered a high risk of bias. A risk of $50 \%$ to $70 \%$ is considered a moderate risk of bias, and a risk level above $70 \%$ is considered a low risk of bias.

\section{RESULTS}

A total of 336 articles from the searched databases were deposited into the Rayyan QRCl database. After 72 duplicates were excluded, 264 articles remained for abstract review. Of these, 260 articles were excluded according to the pre-established selection criteria. Finally, only four articles met the eligibility criteria and were read in full by all authors. The articles were then subjected to risk of bias analysis, and one of the articles - Hernández et al. - was excluded because its high risk of bias and its lack of scientific rigor made it adequate for this qualitative synthesis.

\section{DISCUSSION}

In a prospective and controlled clinical trial, Menendez, S., Del Cerro A., et al. evaluated the efficacy of ozone therapy for the treatment of 50 patients with peripheral vestibulocochlear syndrome. Ozone was injected into the cervical region at $\mathrm{C} 2-\mathrm{C} 3$, on both sides of the spinal process (twice a week for 20 sessions). Their patients obtained improvements in vertigo, hearing loss, tinnitus and nystagmus of $90 \%, 80 \%, 65 \%$ and $100 \%$, respectively. Therefore, the authors concluded that ozone therapy is effective for the treatment of peripheral vestibulocochlear syndrome. They reported that patients were initially under systemic oxidative stress; however, at the end of the study, a redox balance was achieved. No side effects were observed. Sonmez O, et al. conducted a randomized, prospective and controlled study that investigated the effects of ozone and betahistine on tinnitus in 68 patients. A total of 10 ozone treatment sessions were administered to 27 patients in the ozone group via major autohemotherapy twice a week. Twenty-six patients in the beta-histatin group received oral betahistine tablets $48 \mathrm{mg} /$ day for three months. Fifteen patients who were eligible for the study but refused treatment were followed up without any treatment. In conclusion, the two treatment methods that were indicated to be effective for tinnitus seemed to have limited beneficial effects. This may be explained by the fact that tinnitus is of multifactorial origin. Therefore, the study did not provide sufficient evidence to support ozone and betahistine as treatments for tinnitus.
The authors suggested that more studies should focus on the early stages of tinnitus. During the study, no side effects were observed.

In a clinical trial, Pawlak, Osinka $\mathrm{K}$, et al. used ozone and pulse pressure therapies for the treatment of Ménière's disease in a total of 15 patients - eight men and seven women aged between 38 and 56 years; their mean age was 43.7 years. Typical symptoms were observed: sensorineural hearing loss, tinnitus attacks, vertigo and nausea and even vomiting. The ozone and pressure pulse treatments were performed simultaneously. The concentration of ozone in the ozone and oxygen mixture was $8 \mathrm{mg} / \mathrm{liter}$; the flow rate was $60 \mathrm{~mL} / \mathrm{min}$. Inhalation was performed for 10 minutes per day once a day for 10 days. Auditory membrane massage was performed for five minutes three times a day for one week. The authors concluded that there was a tendency for improvement with the studied therapies, but statistically significant results were not obtained. However, the subjective state of the patients improved, and there was a reduction in the frequency and severity of tinnitus. In some patients, this result lasted for two years. A relevant finding is that no attacks occurred in some patients who were observed for an additional month. After treatment, tinnitus disappeared completely in four patients.

\section{CONCLUSION}

Ozone therapy may be a potential treatment for tinnitus. High-level evidence, such as well-conducted randomized clinical trials, are still needed to confirm the efficacy and safety of this therapy.

\section{CONFLICT OF INTEREST}

The authors declares no conflict of interest

\section{REFERENCES}

1. Teixeira LS, Granjeiro RC, De Oliveira CAP, Júnior FB. Polysomnography applied to patients with Tinnitus: A review. Int Arch Otorhinolaryngol. 2018;22:177-80.

2. Palumbo DB, Joos K, Ridder D De, Vanneste S. The Management and Outcomes of Pharmacological Treatments for Tinnitus. 2015;692-700.

3. Fernandes G, Siqueira JTT de, Gonçalves DA de G, Camparis CM. Association between painful temporomandibular disorders, sleep bruxism and tinnitus. Braz Oral Res. 2014;28:1-7.

4. Garcia de Hombre AM. Painful disorder and vertigo related to the ear. Frequent referral to the ENT specialist. An Med Interna. 2005;22:88-90.

5. Baguley D, McFerran D, Hall D. Tinnitus. Lancet. 2013;382:1600-7.

6. Ahmad N, Seidman M. Tinnitus in the older adult: Epidemiology, pathophysiology and treatment options. Drugs and Aging. 2004;21:297-305.

7. McCormack A, Edmondson-Jones M, Somerset S, Hall D. A systematic review of the reporting of tinnitus prevalence and severity. Hear Res. 2016;337:70-9. 
8. Yuan T, Yadollahpour A, Salgado-Ramírez J, Robles-Camarillo D, Ortega-Palacios R. Transcranial direct current stimulation for the treatment of tinnitus: A review of clinical trials and mechanisms of action 11 Medical and Health Sciences 1103 Clinical Sciences. BMC Neurosci. 2018;19:66.

9. Wang TC, Tyler RS, Chang TY, Chen JC, Lin C Der, Chung HK, et al. Effect of Transcranial Direct Current Stimulation in Patients With Tinnitus: A Meta-Analysis and Systematic Review. Ann Otol Rhinol Laryngol. 2018;127:79-88.

10. Spiegel R, Kalla R, Mantokoudis G, Maire R, Mueller H, Hoerr R, et al. Ginkgo biloba extract EGb $761{ }^{\circledR}$ alleviates neurosensory symptoms in patients with dementia: A meta-analysis of treatment effects on tinnitus and dizziness in randomized, placebo-controlled trials. Clin Interv Aging. 2018;13:1121-7.

11. Mota A, Cavalcante G, Monteiro I, Silva DC, Jessica B, Augusto $C$, et al. Degree of tinnitus improvement with stapes surgery -. Braz J Otorhinolaryngol. 2018;84:514-518.

12. Menendez S, del Cerro A, Alvarez T, Hernandez F. Application of Ozone Therapy in the Vestibulocochlear Syndrome. Rev Recent Clin Trials. 2012;7:321-8.

13. Sönmez O, Külahli I, Vural A, Şahin MI, Aydin M. The evaluation of ozone and betahistine in the treatment of tinnitus. Eur Arch Oto-Rhino-Laryngology. 2013;270:1999-2006.

14. Pawlak-osinska K, Kazmierczak H, Kazmierczak W, Szpoper M. Ozone Therapy and Pressure-Pulse Therapy in Meniere's Disease. 2004;10:54-7.

15. Armando Figueroa Hernández, Juan M. Salomón Bacallao ADG. Ozonoterapia en Otorrinolaringología. Estudio de cinco años Ozone. Medisur. 2005;3:53-7.

16. Bocci VA. Scientific and medical aspects of ozone therapy. State of the art. Riv Ital di Ossigeno-Ozonoterapia. 2006;5:93-104.

17. Smith NL, Wilson AL, Gandhi J, Vatsia S, Khan SA. Ozone therapy: an overview of pharmacodynamics, current research, and clinical utility. Med Gas Res. 2017;7:212-9.
18. Seyam O, Smith NL, Reid I, Gandhi J, Jiang W, Khan SA. Clinical utility of ozone therapy for musculoskeletal disorders. Med Gas Res. 2018;8:103-10.

19. O.S. Leon SM. Ozone oxidative preconditioning : A protection against cellular damage by free radicals. 1998;294:289-94.

20. Bocci VA. Scientific and Medical Aspects of Ozone Therapy . State of the Art. 2006;37:425-35.

21. Bocci V, Zanardi I, Travagli V. Oxygen/ozone as a medical gas mixture. A critical evaluation of the various methods clarifies positive and negative aspects. Med Gas Res. 2011;1:6.

22. Braidy N, Izadi M, Sureda A, Jonaidi-Jafari N, Banki A, Nabavi SF, et al. Therapeutic relevance of ozone therapy in degenerative diseases: Focus on diabetes and spinal pain. $J$ Cell Physiol. 2018;233:2705-14.

23. William, A PLS. The cascade mechanism to explain ozone toxicity :The role of lipid ozonation products. 1995;19:935-41.

24. Arias-Vázquez PI, Tovilla-Zárate CA, Hernández-Díaz Y, González-Castro TB, Juárez-Rojop IE, López-Narváez ML, et al. Short-Term Therapeutic Effects of Ozone in the Management of Pain in Knee Osteoarthritis: A Meta-Analysis. Pm\&r. 2019;11:879-87.

25. Fitzpatrick E, Holland OJ, Vanderlelie JJ. Ozone therapy for the treatment of chronic wounds: A systematic review. Int Wound J. 2018;15:633-44.

26. Domb WC. Ozone therapy in dentistry. A brief review for physicians. Interv Neuroradiol. 2014;20:632-6.

27. Andrade RR de, Oliveira-Neto OB de, Barbosa LT, Santos IO, Sousa-Rodrigues CF de, Barbosa FT. [Effectiveness of ozone therapy compared to other therapies for low back pain: A systematic review with meta-analysis of randomized clinical trials]. Rev Bras Anestesiol. 2019;69:493-501.

28. Valadares $C$. Ministério da Saúde inclui 10 novas práticas integrativas no SUS. Brasília, DF. 2018.

29. Riera R, Braga VL, Rocha LP dos S, Bernardo DD, de Andrade LAF, Hsu JC, et al. What do cochrane systematic reviews say about new practices on integrative medicine? Sao Paulo Med J. 2018;136:251-61. 